\title{
Simulation of Transcritical Flow in Hydraulic structures
}

\author{
Cornelius E. Agu ${ }^{1} \quad$ Geir Elseth $^{2} \quad$ Bernt Lie $^{3}$ \\ ${ }^{1,3}$ Faculty of Technology, Telemark University College, Norway, \{cornelius.e.agu, bernt.lie\}@hit.no \\ ${ }^{2}$ Statoil AS, Norway, geielestatoil.com
}

\begin{abstract}
In hydraulic engineering, transcritical flows are often required in some applications. One example is in a Venturi channel where the occurrence of critical depth is used to estimate flow rate in the channel. In this paper, a simple numerical scheme that predicts transcritical flows in hydraulic structures is developed based on the Saint Venant Equations (SVE). The solution of this scheme is aimed to be used in real time to calibrate the model that uses a measured liquid level to estimate flow rate of the fluid in a Venturi channel. The proposed algorithm consists of a set of ordinary differential equations derived from discretizing SVE in space along the channel axis. The results based on this scheme show that the algorithm is capable of predicting flows involving transcritical conditions. Errors associated with the scheme are relatively small in locating shocks in flows with imposed downstream boundary level, and in predicting the transition within the throat of Venturi channels.
\end{abstract}

Keywords: Transcritical, Saint Venant Equations, Critical Depth, Hydraulic Structures, Boundary Condition

\section{Introduction}

As it is encountered in natural channels such as river flow, open channel flow usually transits from one flow condition to another due to bed slope changes and variation in channel width. These conditions are classified into subcritical where the flow velocity is less than the gravity wave celerity ${ }^{1}$, supercritical in which the flow velocity is greater than the wave speed (celerity) and critical flow condition where the flow velocity and celerity are the same. When there is a change from one flow condition to another, the condition is regarded as transcritical flow.

In artificial hydraulic structures, transcritical flows are often introduced to establish a relationship between flow rate and the free stream level. This condition is widely utilized in Venturi channels and weirs for flow measurements.

The possibility of estimating drilling mud flow rate for kick/loss detection using a Venturi channel flow rate model has been previously studied, and the studies show that the required tuning parameter for the model depends on the fluid properties due to non-Newtonian behaviour of the fluid (Agu and Lie, 2014; Berg et al, 2015). One possibility of making the flow rate model applicable for software development in real time is to calibrate the model with a 1-D unsteady state model that describes the flow in the channel. The Saint Venant Equations have been long established as a good 1-D model that predicts the flow behaviour in an open channel. Most algorithms for simulating the model predict flow accurately in pure subcritical and pure supercritical conditions. Due to its numerical challenges, algorithms available for simulating transcritical flow require either modification of the Saint Venant Equations or imposing internal boundary at critical depth whose location is certainly unknown.

The purpose of this study is to develop a numerical scheme that solves the Saint Venant Equations across a critical flow condition. Such a scheme is used in real time to calibrate the Venturi channel model that uses a measured liquid level to estimate flow rates in the channel, which ensures high accuracy in drilling mud flow rate measurement using a Venturi channel.

(Meselhe et al, 1997) developed a two-step predictorcorrector implicit scheme for simulating transcritical flow based on SVE. They included an artificial dissipation terms to suppress numerical oscillations around stiff regions, so to facilitate hydraulic jumps resolutions. (Zerihun and Fenton, 2006) presents a onedimensional model for steady state transcritical free surface flows based on a Boussinesq-type equation. They argued that due to involvement of a short length within which transcritical flow occurs, the pressure distribution is not hydrostatic and the Saint Venant Equations are not valid. (Sart et al, 2010) developed a scheme based on the modified Preissman method. As Preissman scheme solves only pure subcritical and supercritical flows, they adopted the scheme and included the condition for imposing internal boundary condition where critical flow occurs.

In this paper, a numerical scheme for solving transcritical flow using unmodified SVE is presented. The equations are discretized in space using the finite

\footnotetext{
${ }^{1}$ Wave celerity $=\sqrt{\frac{A g}{B}}$, is defined as the velocity of a wave

propagating in a flowing liquid relative to the liquid.
} 
volume approach into a set of ordinary differential equations (ODE). The boundary condition equations are formulated based on a combination with physical boundary condition that satisfies the continuity equation. The scheme is simulated and the results are compared with published results and with the experimental values obtained from a Venturi rig set up at Telemark University College, Norway.

In the following sections, the governing equations are presented, and the experimental setup is described. The numerical scheme solution is compared with results from the experiment and from the literature. Finally, some conclusions are drawn.

\section{Governing Equations}

The unsteady state flow of fluid in an open channel can be described by the one-dimensional Saint Venant Equations (Szymkiewicz, 2010),

$$
\frac{\partial A}{\partial t}+\frac{\partial Q}{\partial x}=0
$$

$\frac{\partial Q}{\partial t}+\frac{\partial\left(\frac{\beta Q^{2}}{A}\right)}{\partial x}=g A \sin \theta-g A \cos \theta \frac{\partial h}{\partial x}-g A S_{f}$.

Equations (1) and (2) are based on mass conservation and momentum conservation principles, respectively, where $Q$ is the volume flow rate, and $A$ and $h$ are the flow cross sectional area and free surface level, respectively. $\theta$ is the channel angle of inclination, and $g$ is the acceleration due to gravity. $\beta$ is a momentum correction coefficient with a value between 1.03 and 1.07 .

For a Newtonian fluid, the frictional slope $S_{f}$ is given by Manning's equation,

$$
S_{f}=\left(|V| n_{M}\right)^{2} R_{h}^{-4 / 3} .
$$

For a non-Newtonian fluid flow, the internal frictional shearing stresses dominate. Based on power law fluid rheology, $S_{f}$ is given by Eq. (4) which is derived from the velocity distribution function across the fluid depth as given in (Sisson et al, 2012).

$$
S_{f}=\frac{K}{4 \rho g R_{h}}\left(\frac{|V|}{h} \frac{1+2 n}{n}\right)^{n}
$$

Here, $n_{M}$ is Manning's roughness coefficient, $h$ is the free surface liquid level, $V=Q / A$ is the average flow velocity and $R_{h}=\frac{A}{P_{\text {wet }}}$ is the hydraulic radius at each cross section.

\subsection{Solution Algorithm - ODE Scheme}

The numerical scheme presented here for solving the unsteady state equations (1) and (2) is based on the finite volume method with staggered grid which ensures that the varying slope of the liquid surface is captured (Versteeg and Malalasekera, 2007). Figure 1 shows the grid arrangement.

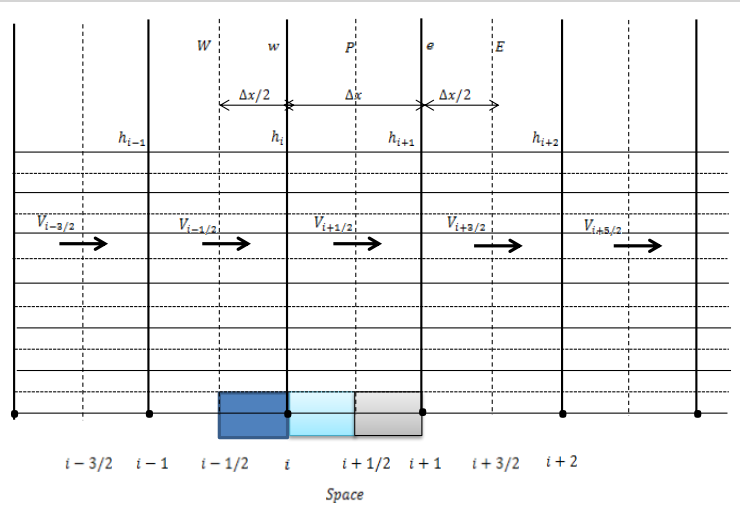

Figure 1: Staggered grid arrangement for mass and momentum control volumes.

For a positive flow ${ }^{2}$, the scheme described by a set of ordinary differential equations (ODE) is given by Eqs. (5)-(10).

$$
\begin{gathered}
\frac{d A_{i}}{d t}=-\frac{Q_{i+1 / 2}-Q_{i-1 / 2}}{\Delta x} \\
\frac{d Q_{i+1 / 2}}{d t}=-\beta \frac{(Q V)_{i+1}-(Q V)_{i}}{\Delta x}-g \bar{A}_{i+1 / 2} \cos \theta \frac{h_{i+1}-h_{i}}{\Delta x}+ \\
g \bar{A}_{i+1 / 2} S_{i+1 / 2} \\
S_{i+1 / 2}=\sin \theta-S_{f i+1 / 2} \\
Q_{i}=\frac{Q_{i+1 / 2}+Q_{i-1 / 2}}{2} \\
\bar{A}_{i+1 / 2}=f\left(\frac{h_{i+1}+h_{i}}{2}\right)
\end{gathered}
$$

By a first order upwind condition, the momentum flux, $(Q V)_{i}$ is given as in Eq. (10)

$$
(Q V)_{i}=\frac{Q_{i+1 / 2}+Q_{i-1 / 2}}{2} V_{i-1 / 2}
$$

The indices, $i=1,2,3, \ldots, N$ indicate the computational nodes along the channel length. The first node in this scheme is at $i=1$, and it interacts with the left physical boundary. The last node is at $i=N$ which corresponds to the right physical boundary.

The detailed derivation and description of Eqs. (1)-(2) and Eqs. (5)-(10) can be found in (Agu, 2014).

\footnotetext{
${ }^{2}$ Positive flow occurs when $\frac{Q_{i+1 / 2}+Q_{i-1 / 2}}{2} \geq 0$
} 


\subsection{Boundary Equations}

At the upstream boundary, the values of $h(x=0)$ and $Q(x=0)$ are designated as input corresponding to $h_{0}$ and $Q_{1 / 2}$, respectively. The downstream boundaries are $h(x=L)$ and $Q(x=L)$ corresponding to $h_{N}$ and $Q_{N+1 / 2}$, respectively; see Figure 2. Normally, $Q(x=0)$ is specified along with any of $h(x=0)$ and $h(x=L)$ depending on the flow condition.

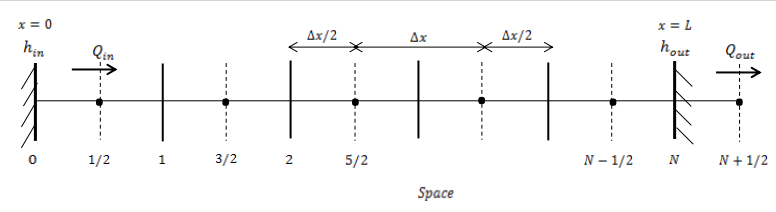

Figure 2: Position of $h$ and $Q$ cells at the domain boundaries.

The boundary equations are only formulated for downstream boundaries where the last computational node correspond to the physical boundary. When $h_{N}(t)$ is given, $\frac{d A_{N}}{d t}$ is known. $Q_{N+1 / 2}(t)$ is obtained from Eq. (11) such that the mass balance, Eq. (5) is satisfied.

$$
Q_{N+1 / 2}=Q_{N-1 / 2}-\Delta x \frac{d A_{N}}{d t} \text {. }
$$

When $Q_{N+1 / 2}(t)$ is given, $A_{N}$ is obtained by integrating Eq. (5) over time.

$$
A_{N}=\int\left(-\frac{Q_{N+1 / 2}(t)-Q_{N-1 / 2}}{\Delta x}\right) d t
$$

For a pure subcritical flow, both upstream and downstream boundaries must be specified with a combination of level and flow rate. In a pure supercritical flow, only the upstream boundary is specified with the flow variables $h(x=0)$ and $Q(x=$ $0)$. When the flow transits from subcritical upstream to supercritical downstream, only the upstream flow rate is used to determine the flow behaviour. The downstream boundary flow rate can be obtained from Eq. (13), which is derived from Eq. (6)

$\frac{d Q_{N+1 / 2}}{d t}=-\frac{\beta}{2 \Delta x}\left(\frac{2 Q_{N+\frac{1}{2}}^{2}}{\bar{A}_{N+\frac{1}{2}}}-\frac{\left(Q_{N+\frac{1}{2}}+Q_{N-\frac{1}{2}}\right) Q_{N-\frac{1}{2}}}{\bar{A}_{N-\frac{1}{2}}}\right)+$

$g \bar{A}_{N+1 / 2} S_{N+1 / 2}$.

\subsection{Simulation Execution}

The accuracy of the scheme described by Eq. (5) through Eq. (13) is of first order since the scheme is based on a first order upwind condition. Its stability depends on the initial condition and on the ODE solver for its implementation. The ode 23 and ode 45 can be used in pure subcritical and pure supercritical problems. When the problem involves transcritical, the scheme suffers convergence problem when implemented on ode 23 or ode 45 , especially in the region of shock propagation. The ode $15 \mathrm{~s}$ can efficiently be used to implement the scheme in all problems including transcritical cases.

When an adaptive time step is used in the solver, the number of grids used does not affect the stability of the scheme, but the accuracy and speed of execution. Where the problem does not involve shock wave propagation, 50 grids can be sufficient. In stiff problems such as that involving transition from supercritical to subcritical flow condition, larger number of grids in the range of 100 to 500 will be required.

Moreover, the convergence of the scheme to a solution solely depends on the initial condition. A uniform liquid level (not necessary a normal level) can be used to initialize the scheme for any flow rate, but the chosen level must not be less than the highest level (mainly the imposed boundary level) that can be achieved in the flow.

By using the right frictional slope model, the scheme can be used to simulate flows of all conditions characterized by both Newtonian and non-Newtonian fluid behaviours.

\section{Experimental Setup}

At Telemark University College, Norway, a Venturi channel test rig was set up. The rig is used to validate the model established to predict a flow through an open channel, and to study the possibility of applying a Venturi channel model for estimating the flow rate of drilling mud in an open channel, in both steady and unsteady state conditions.

The rig consists of a trapezoidal channel of total length $3.70 \mathrm{~m}$ and height $0.3 \mathrm{~m}$. The geometry of the channel is shown in Figure 3, and the description of parts and dimensions are given in Table 1.

The complete circuit of the rig is made up of a series of equipment including a mud mixing tank, a mud circulating pump (screw type) with capacity up to 1000 $\mathrm{kg} / \mathrm{min}$, a 100 liter Venturi channel intake tank and a mud return tank. All the equipment is linked by a set of stainless steel pipes of appropriate sizes between two adjoining equipment. There are a set of sensing instruments measuring different flow properties in real time. A Coriolis mass flow meter measuring up to 600 $\mathrm{kg} / \mathrm{min}$ was installed between the pump and the channel intake tank to measure the flow rate and density of the flowing fluid. The pressure transmitter at the outlet of the pump keeps track of pressure in the line for safe pump operation. Also, the fluid temperature is monitored with a temperature transmitter at the pump outlet. A differential pressure transmitter on the line before the intake tank monitors the pressure drop over a 3 meter horizontal pipe section, and this gives indication 
of viscosity of the flowing fluid. Over the Venturi channel, three ultrasonic level transmitters were mounted on a bar positioned at the center along the axis of the channel. Each of the transmitters can be moved relatively along the bar for measuring the level of flow at any defined position marked on a graduated rule attached to the bar.

The Venturi channel is supported at the upstream end on a hinged support and at downstream end on a pneumatic piston-cylinder assembly. This arrangement provides a freedom for tilting the channel down to $2.5^{0}$ from the horizontal.

The fluid tested is a modeled fluid which exhibits zero-yield pseudoplastic non-Newtonian fluid behaviour. The fluid consists of water, xanthan gum and potassium carbonate.

The Coriolis mass flow meter is still within its certified period of accuracy, and each of the level sensors was calibrated against a uniform solid block of known thickness.

The only challenge with the setup is ensuring accurate level measurement. Due to formation of foam and turbulences in the flow, there is significant irregularities on the fluid surface in the channel. This results in nonuniform fluctuations in the measurements given by each of the level sensors. The measurement results reported in this paper are average values at each location for a sensor reading taken over a period of 5 minutes.

\section{Results and Discussions}

The results of three cases considered are presented here. In Case 1, the simulated results based on the developed algorithm are compared with the experimental data. Case 2 compares the results of the proposed scheme with results from a literature, and Case 3 is used to demonstrate the capacity of the proposed scheme to handle unsteady state behaviours. In the first two cases, steady state flows are considered.

Because the flow properties need to be transported across a critical depth from upstream, the conservative form of the Saint Venant Equations is necessary. Any steady state model derived from SVE looses this conservativeness, and breaks at the critical points (that is, such a model does not give solutions across the critical depth) (Berg et al, 2015). The steady state solutions are obtained from solving the dynamic model described by Eqs. (5)-(13).

\subsection{Case 1 - Venturi Channel}

In the setup described in section 3, a flow at $300 \mathrm{~kg} / \mathrm{min}$ was studied at its steady state in the channel. The flowing fluid has a density of $1109 \mathrm{~kg} / \mathrm{m} 3$, and rheolo-
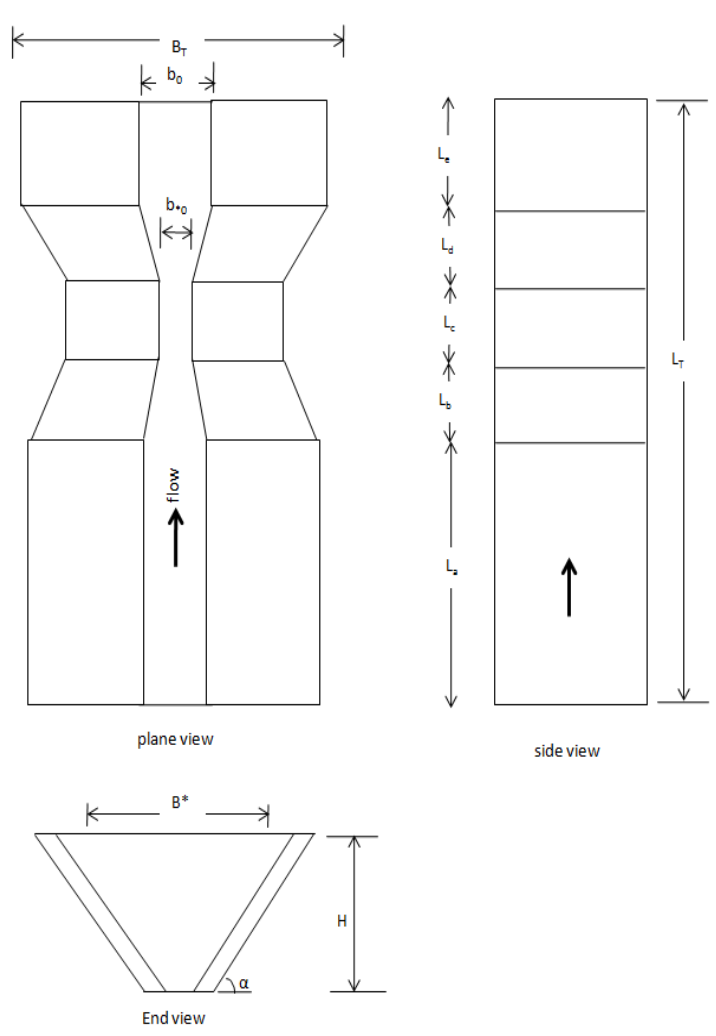

Figure 3. Geometry of a trapezoidal Venturi channel.

Table 1. Dimension of the Venturi flume in the rig $^{3}$.

\begin{tabular}{|c|l|l|}
\hline Symbol & Descriptions & Values \\
\hline$B_{T}$ & $\begin{array}{l}\text { Top width of entrance to the } \\
\text { converging section }\end{array}$ & 0.455 \\
\hline$B_{*}$ & $\begin{array}{l}\text { Top width of exit from the } \\
\text { converging section }\end{array}$ & 0.355 \\
\hline$b_{0}$ & $\begin{array}{l}\text { Bottom width of entrance to } \\
\text { the converging section }\end{array}$ & 0.20 \\
\hline$b_{* 0}$ & $\begin{array}{l}\text { Bottom width of exit from the } \\
\text { converging section }\end{array}$ & 0.10 \\
\hline$H$ & \begin{tabular}{l} 
Total height of the channel \\
\hline$\alpha$
\end{tabular} & $\begin{array}{l}\text { Slope of the inclined sides of } \\
\text { the channel }\end{array}$ \\
\hline$L_{a}$ & $\begin{array}{l}\text { Length of the upstream } \\
\text { section }\end{array}$ & 70.35 \\
\hline$L_{b}$ & $\begin{array}{l}\text { Length of the converging } \\
\text { section }\end{array}$ & 0.15 \\
\hline$L_{c}$ & Length of the throat section & 0.20 \\
\hline$L_{d}$ & $\begin{array}{l}\text { Length of the diverging } \\
\text { section }\end{array}$ & 0.15 \\
\hline$L_{e}$ & $\begin{array}{l}\text { Length of the downstream } \\
\text { section }\end{array}$ & 0.25 \\
\hline$L_{T}$ & Total length of the channel & 3.70 \\
\hline
\end{tabular}

\footnotetext{
${ }^{3}$ In Table 1, the angle is in degree and side lengths in meters.
} 
gical parameters of $\tau_{y}=0, n=0.5855$ and $K=$ 0.0631 Pa.s ${ }^{\mathrm{n}}$. The channel was inclined at $0.08^{0}$.

The first measurement of the liquid level was taken at a position $2.18 \mathrm{~m}$ from the channel inlet, from where the liquid surface was somewhat stable. Subsequent level measurements to develop the profile of the flow, were taken at an interval of $10 \mathrm{~cm}$ before the throat, and at an interval of $5 \mathrm{~cm}$ from the throat to the last point $(1.35 \mathrm{~m}$ from the first point).

The simulation of the model starts at a point $1.78 \mathrm{~m}$ from the leading end until the end of the channel. A total of 50 computational nodes was used, and the simulation was performed using MATLAB ode15s solver.

The dynamic model was simulated with initial conditions of $0.07 \mathrm{~m}$ for the level and $4.51 \mathrm{lit} / \mathrm{s}$ for flow rate until a steady state is reached. The results from the model simulation and the experimental data are shown in Figure 4.

Due to contraction of the channel before the throat, the liquid level decreases towards the throat. As can be seen in Figure 4, the flow passes through its critical depth within the throat. Since the flow is a free-flow (no imposed downstream boundary level), the flow remains supercritical after the critical point until the end. The figure shows that there is a good agreement between the simulated results and the experimental data. The simulated results deviate slightly from the experimental data after the flow reaches the critical depth and before the entrance to the downstream uncontracted section. This behaviour may be due to deviation of pressure distribution from the assumed hydrostatic distribution. The relative error associated with this scheme around this region is small as can be seen in the figure.

The flow profile given in Figure 4 is based on the average liquid level in the center line of the flow, assuming the flow occupies the full flow cross section at that level. The experimental study shows that the flow cross section remains full in the approaching section, and nearly full up to the entrance of the uncontracted section at the end. Within the uncontracted section, there is a strong effect of boundary layer, causing a drift of the fluid towards the channel walls. This effect reduces the centerline flow depth below its average value across every cross section in that region.

Figure 5 shows the profile of average velocity of the flow along the channel. Comparing with the critical velocity (wave celerity), which is about $0.673 \mathrm{~m} / \mathrm{s}$ within the throat region, it can be seen that critical flow actually occurs within the throat, around $3.22 \mathrm{~m}$ from the leading end. Below this point, the flow is subcritical $(\mathrm{V}<0.673 \mathrm{~m} / \mathrm{s})$ and beyond it, the flow is supercritical $(\mathrm{V}>0.673 \mathrm{~m} / \mathrm{s})$.

\subsection{Case 2 - Steep Chute Channel}

This case considers a steep chute channel connecting a river to a reservoir. The channel has a rectangular crosssection of width $8 \mathrm{~m}$, and length $1000 \mathrm{~m}$. The channel is divided into three regions with lengths $300 \mathrm{~m}, 300 \mathrm{~m}$ and $400 \mathrm{~m}$, and bed slope 0.002, 0.009 and 0.001 , respectively.

A steady state flow of water with flow rate of $20 \mathrm{~m}^{3} / \mathrm{s}$ through the channel is studied. The downstream imposed water level is $2.5 \mathrm{~m}$, and Manning's roughness coefficient is chosen as 0.015 . A similar example was published in (Meselhe et al, 1997).

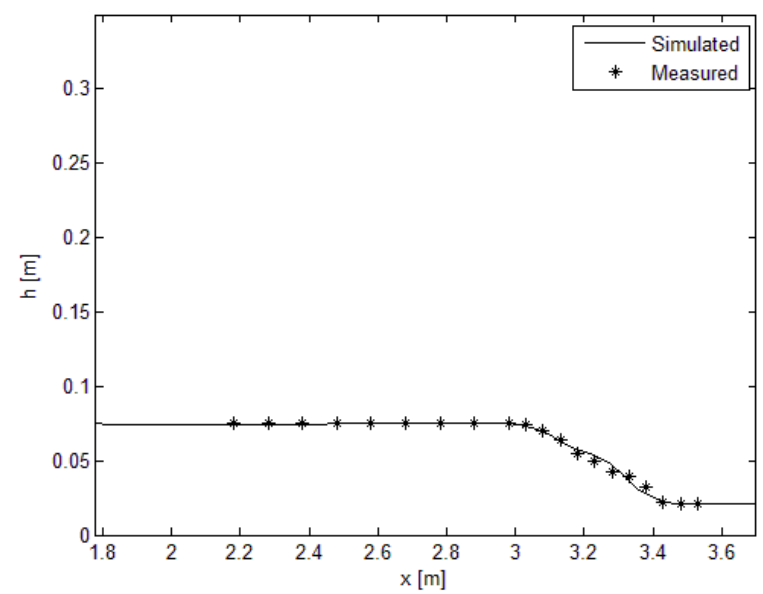

Figure 4. Level of the mudflow along the Venturi channel.

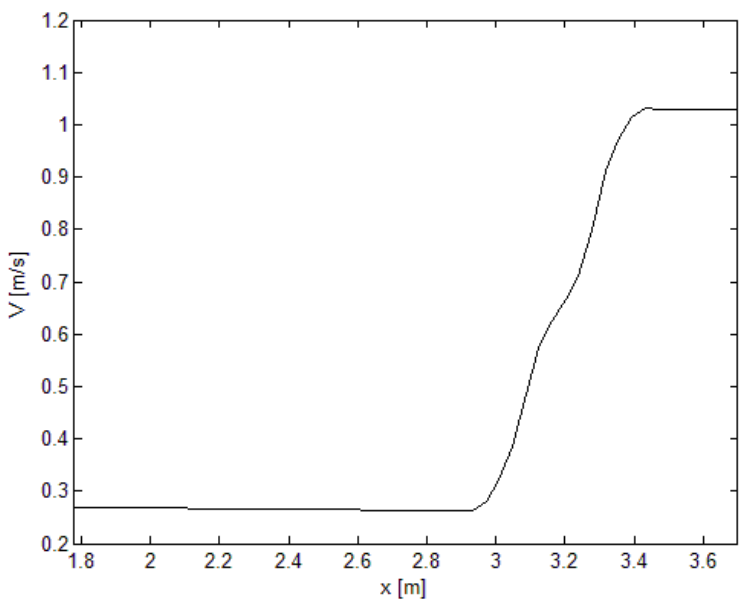

Figure 5. Velocity of the mudflow along the Venturi channel.

The model simulation was based on the dynamic model with initial conditions $20 \mathrm{~m}^{3} / \mathrm{s}$ for the flow rate, and $4.5 \mathrm{~m}$ for the water level for all computation points except the last node with imposed boundary condition of $2.5 \mathrm{~m}$. Uniform grid of size $2 \mathrm{~m}$ was used compared to $20 \mathrm{~m}$ used in the literature. The simulation was performed using MATLAB ode15s solver.

The result obtained with the proposed scheme compared with a MESH scheme (Meselhe et al, 1997) is given in Figure 6. As can be seen in Figure 6, due to changes in the channel slope, the flow changes from subcritical flow in the first region to supercritical flow in the second region. There is an hydraulic jump before the end of the second region, returning the flow back to subcritical flow due to the imposed downstream water 
level and due to the decrease in the channel slope at the last region. Critical depths are attained at the connecting point between the first two regions and somewhere during the shock propagation in the second region.

Figure 6 shows that the ODE scheme gives the same results as the MESH scheme except where the shock is located. The shock starts slightly later as given by the ODE scheme than as computed in the MESH scheme. The analytical result given in (Meselhe et al, 1997) shows that the shock location lies between the results given by MESH scheme and ODE scheme. Based on this, it can be inferred that the associated error with ODE scheme in predicting the shock is relatively small.

Figure 7 shows the evolutions of the upstream level and the level at midway of the channel. The result shows that the numerical scheme (ODE scheme) is stable, converging to steady state solution from the initial condition in about 10 minute without oscillations, and even appearance of shock as noted in midway of the channel does not influence its stability.

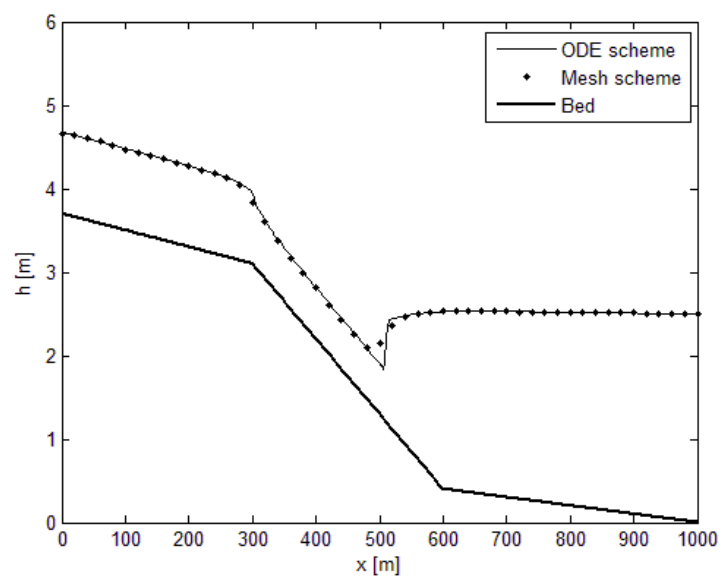

Figure 6. Profile of water flow in the steep chute channel.

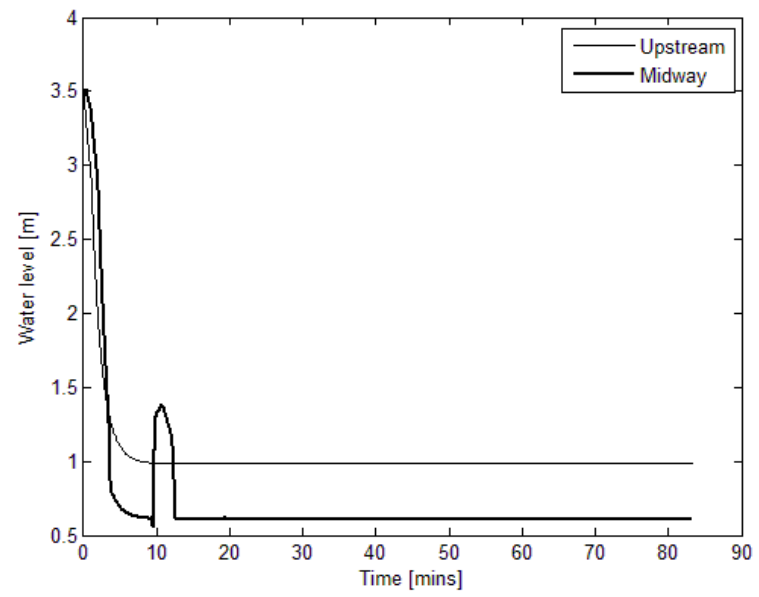

Figure 7. Evolution of water level with time in the steep chute channel.

\subsection{Case 3 - Dynamic Flood Routing}

To demonstrate the dynamic capability of the proposed scheme, consider its application to dynamic flood routing that is required for river planning and control.
Figure 8 shows a series of computed water level during a flood event in a $10 \mathrm{~m}$ wide rectangular channel comprising four reaches: $\left(S_{1}=0.006, L_{1}=500 \mathrm{~m}\right)$, $\left(S_{2}=0.001, L_{2}=500 \mathrm{~m}\right),\left(S_{3}=0.006, L_{3}=500 \mathrm{~m}\right)$ and $\left(S_{4}=0.001, L_{4}=500 \mathrm{~m}\right)$. At the downstream boundary, a depth-discharge rating curve $(Q=$ $27.5 h^{1.67}$ ) is imposed, and at the upstream boundary, the hydrograph, $Q(t)$ described in Eq. (14) is imposed (Tseng et al., 2001). Manning's roughness coefficient is chosen as 0.02 .

It can be seen in Figure 9 that the flowrate downstream attains the same peak value as the upstream flowrate. This shows that the volume of water in the channel is conserved during the flood event, despite the rise in the wave amplitude as depicted in Figure 10, where the peak level downstream is higher than the peak level upstream. Figure 8 also shows that the surge gradually moves upstream during the period the hydrograph rises, and downstream during the falling period of the hydrograph.

$$
\begin{aligned}
& Q(t)= \\
& \left\{\begin{array}{c}
1.0 \mathrm{~m}^{3} / \mathrm{s} ; 0 \leq t \leq 20 \mathrm{mins} \\
1.0+75\left[1-\cos \left(\frac{2 \pi(t-20)}{120}\right)\right] ; \quad 20 \leq t \leq 140 \mathrm{mins} \\
1.0 \mathrm{~m}^{3} / \mathrm{s} ; \quad 140 \leq t \leq 180 \mathrm{mins}
\end{array}\right.
\end{aligned}
$$

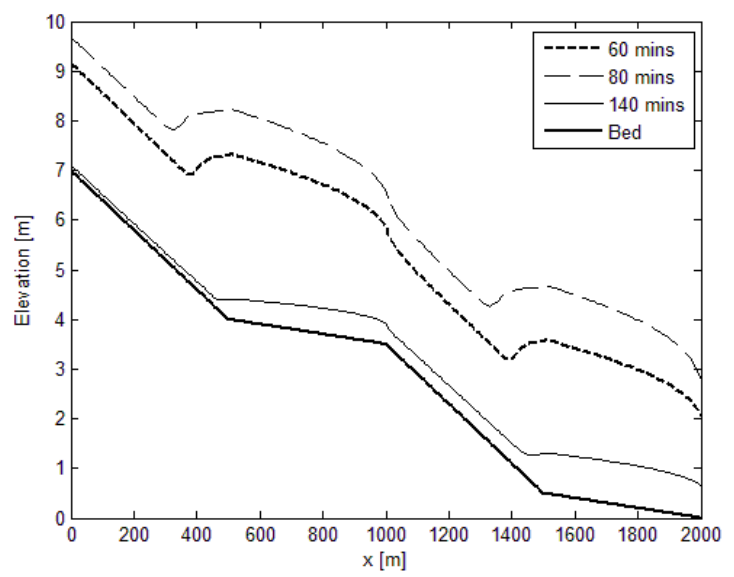

Figure 8. Profile of water level during hydrograph inflow.

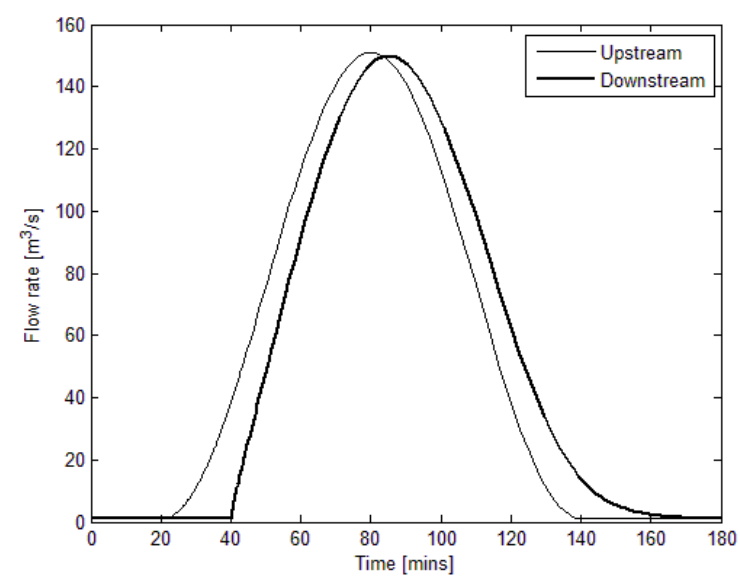

Figure 9. Evolution of hydrograph flow. 


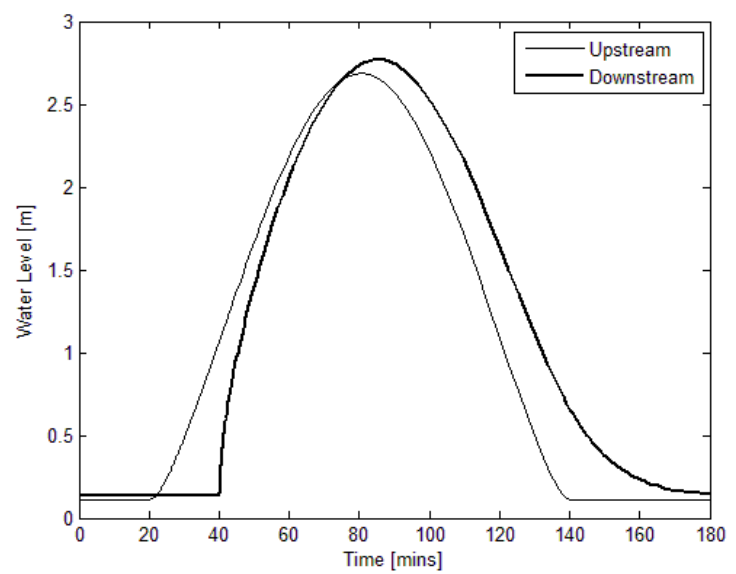

Figure 10. Evolution of upstream and downstream water levels.

\section{Conclusions}

In this paper, the Saint Venant Equations are discretized into a set of ordinary differential equations. A simple numerical algorithm (ODE scheme) based on these discrete equations is proposed for simulating transcritical flows in an open channel. The results show that by using an appropriate grid size and choosing the right ode solver, the scheme gives results which are in good agreement with some existing scheme.

The scheme is validated against experimental data obtained for a flow of mud in a Venturi channel, which confirms the applicability of the scheme to both Newtonian and non-Newtonian fluid behaviours.

\section{Acknowledgements}

The support from Statoil ASA, the Intelligent Drilling group is gratefully acknowledged.

\section{References}

C. Berg, A. Malagalage, C.E. Agu, G.-O. Kaasa, K. Vaagsaether and B. Lie (2015): Model-Based Drilling Fluid Flow Rate Estimation Using Venturi Flume. Proceedings, 2nd IFAC Workshop on Automatic Control in Offshore Oil and Gas Production, Florianopolis, Brazil, May 27-29, 2015.

C.E. Agu (2014): Model-Based Estimation of drilling mud Flow using a Venturi Channel. Master Thesis Report. Telemark University College, Porsgrunn, Norway, 2014.

C.E. Agu and B. Lie. Numerical Solution of the Saint Venant Equation for Non-Newtonian Fluid. Conference on Simulation and Modelling (SIMS 55), October 21-22, 2014. Aalborg, Denmark.
C. Sart, J.-P. Baume, P.-O. Malaterre and V. Guinot (2010): Adaptation of Preissmann's Scheme for Transcritical Open Channel Flows. Journal of Hydraulic Research, 48(4): 428440, 2010.

E.A. Meselhe, F. Sotiropoulos and F.M. Holly-Jr. (1997): Numerical Simulation of Transcritical Flow in Open Channel. Journal of Hydraulic Engineering, 123(9): 07740783, 1997.

H.K. Versteeg and W. Malalasekera (2007): An Introduction to Computational Fluid Dynamics: Finite Volume Method, $2^{\text {nd }}$ ed. England: Pearson Education Limited, Edinburgh Gate Harlow Essex CM20 2JE, 2007.

M.-H. Tseng, C-A. Hsu and C.R. Chu (2001): Channel Routing in Open Channel Flows with Surges. Journal of Hydraulic Engineering, 127(2): 0115-0122, 2001.

R. Sisson, P. Lacoste-Bouchet, M. Vera, M. Costello, E. Hedblom, B. Sheets and L. Sittoni (2012): An Analytical Model for Tailings Deposition from Pilot-Scale Testing. In Proc. 3rd Int. Oil Sand Tailings Conference, Edmonton, Canada. 2012.

R. Szymkiewicz (2010): Numerical Modeling in Open Channel Hydraulics (Vol.83), Springer, ISBN 978-90-4813673-5, 2010.

T.Y. Zerihun and J.D. Fenton (2006): One-Dimensional Simulation Model for Steady Transcritical Free Surface Flows at Short Length Transitions. Journal of Advances in Water Resources, 29: 1598-1607, 2006. doi:10.1016/j.advwatres.2005.11.011.

\section{Notation}

$A \quad$ Cross sectional area $\left[\mathrm{m}^{2}\right]$

$\bar{A} \quad$ Average cross sectional area $\left[\mathrm{m}^{2}\right]$

$g \quad$ Gravitational acceleration $\left[\mathrm{m} / \mathrm{s}^{2}\right]$

$h \quad$ Free surface level [m]

$K \quad$ Flow behaviour index $\left[\mathrm{Pa} . \mathrm{s}^{\mathrm{n}}\right]$

$L \quad$ Length [m]

$N \quad$ Spatial grid size

$n \quad$ Fluid consistency index

$P_{\text {wet }}$ Wetted perimeter [m]

$Q \quad$ Flow rate $\left[\mathrm{m}^{3} / \mathrm{s}\right]$

$R_{h} \quad$ Hydraulic radius [m]

$S \quad$ Slope

$x \quad$ Distance along a channel axis [m]

$V \quad$ Average velocity $[\mathrm{m} / \mathrm{s}]$

$\Delta x \quad$ The spacing of the grids along the channel [m]

$\beta \quad$ Momentum correction coefficient

$\rho \quad$ Density $\left[\mathrm{kg} / \mathrm{m}^{3}\right]$

$\theta \quad$ Inclination of the channel bottom [degree] 